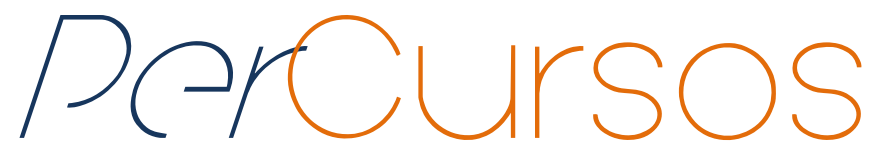

\title{
Memória, identidade cultural e biblioteca comunitária: um estudo de caso em Linha Andréas, em Venâncio Aires - RS
}

\section{Resumo}

Objetiva compreender como a Biblioteca Comunitária da Associação de Leitura, Canto e Jovialidade (A.L.C.J.) de Linha Andréas, em Venâncio Aires, Rio Grande do Sul (RS) auxilia na construção da memória e da identidade cultural da comunidade. Trata de um estudo de caso realizado em 2013 e utiliza como instrumento de coleta de dados a entrevista. Apresenta o caso da Biblioteca Comunitária de Linha Andréas, RS, contextualizando e caracterizando a imigração alemã na localidade, a Associação e a Biblioteca. Analisa as narrativas dos moradores da comunidade sobre a importância da biblioteca por meio de análise de conteúdo. Conclui que a Biblioteca Comunitária de Linha Andréas é um espaço importante dentro da sede, constituindose como patrimônio cultural, pois mantém vivas lembranças do passado, de outras terras, das raízes culturais e da prática da leitura, reforçando laços identitários por meio do seu acervo de língua alemã. Assim, a biblioteca comunitária se constitui um lugar de memória.

Palavras-chave: biblioteca comunitária; memória; identidade cultural.

\author{
Valdir Jose Morigi \\ Doutor em Sociologia pela \\ Universidade de São Paulo. \\ Professor da Universidade \\ Federal do Rio Grande do Sul - \\ Brasil. \\ valdir.morigi@ufgrs.br
}

\section{Ana Paula Sehn}

Bacharela em Biblioteconomia pela Universidade Federal do Rio

Grande do Sul - Brasil. anapsehn@gmail.com

\section{Para citar este artigo:}

MORIGI, Valdir Jose; SEHN, Ana Paula. Memória, identidade cultural e biblioteca comunitária: um estudo de caso em Linha Andréas, em Venâncio Aires - RS. Revista PerCursos. Florianópolis, v. 15, n.29, p. 79 - 102. jun./jul. 2014.

\section{DOI: 10.5965/1984724615292014079}

http://dx.doi.org/10.5965/1984724615292014079 


\title{
Memory, cultural identity and community library: a case study on the of Andreas Line in Venâncio Aires - Rio Grande do Sul
}

\begin{abstract}
The paper aim understanding how the Community Library Association Readers, (A.L.C.J.) from Linha Andréas in the city of Venâncio Aires, Rio Grande do Sul (RS) helps to build social memory and strengthens the cultural identity of local community. It's a study case that took place in 2013 and applied in the data collection interviews with library members, participant observation and documentary research. The work also looks in to the data through content analysis. It reflects on community libraries, social memory, cultural identity and reading practices. Present the case of Linha Andréas' Community Library taking in account the German immigrants descendants in the city, the association members and the library readers. Concludes that the community library of Linha Andréas is an important cultural asset for the community as it revives a forgotten reading habit, but also because it represents a cultural heritage responsible of keeping alive the memory of another land past, reading habits, German language and its culture but also reinforcing identity ties through its collection of German language books. This way, the Library Association Readers represents the place of the community memory.
\end{abstract}

Keywords: community library; memory; cultural identity. 


\section{Introdução}

O objetivo deste artigo é compreender como a Biblioteca da Associação de Leitura, Canto e Jovialidade de Linha Andréas em Venâncio Aires ${ }^{1}$, RS, auxilia na construção da memória e fortalece a identidade cultural da comunidade.

A atual Capital Nacional do Chimarrão, Venâncio Aires, teve seu povoamento por volta do ano de 1800 por açorianos. Por volta de 1853, chegaram os imigrantes alemães provenientes de outras colônias e da Europa. A partir desta data, alguns donos de sesmarias passaram a lotear as terras, transformando-as em colônias exploradas por imigrantes e descendentes de alemães. Estabelecidos preferencialmente no Vale do Sampaio, os alemães de dedicavam à agricultura e foram os responsáveis pela criação de sociedades que existem ainda hoje como espaço de integração, entretenimento, cultura e lazer nas colônias (PREFEITURA, 2013).

O imigrante alemão desde o início demonstrou forte tendência a resolver em comum suas dificuldades, como estava habituado na Europa. De acordo com Flores (1983), a necessidade de convivência com outros após uma semana de trabalho, o desejo de encontrar meios adequados para transmitir os valores culturais germânicos aos seus descendentes e o estabelecimento de medidas previdenciárias, levou o imigrante a desenvolver ações que colocasse em prática seu espírito associativo de maneira própria e intensa. Conforme Flores (1983), em 1924, Venâncio Aires possuía 48 sociedades. Elas estavam distribuídas entre a sede e 20 localidades interioranas, constituindo sociedades de leitura, canto, defesa, música, bolão, damas, entre outras. Algumas destas sociedades sobreviveram, como é o caso da atual Associação de Leitura e Canto Jovialidade de Linha Andréas, com sede própria construída em 1933. Ainda hoje, ela abriga uma biblioteca comunitária criada pelos imigrantes alemães e seus descendentes, com raros livros

\footnotetext{
${ }^{1}$ Venâncio Aires é um município distante 130 quilômetros $(\mathrm{km})$ da Capital Porto Alegre. Tem seus limites traçados ao leste pelos municípios de Mato Leitão, Cruzeiro do Sul e Bom Retiro do Sul; ao oeste com Santa Cruz do Sul; ao norte, com os municípios de Boqueirão do Leão, Santa Cruz do Sul e Sério; ao sul com General Câmara, Taquari, Passo do Sobrado e Vale Verde. Totaliza 728,45 km e mais de 60.000 habitantes (VOGT; GELLER, 2004).
} 
escritos em alemão e alemão gótico, encomendados e trazidos da Alemanha pelos próprios imigrantes que formaram a comunidade no século XIX.

Quanto aos aspectos metodológicos deste trabalho, trata-se de um estudo de caso, definido por Yin (2010, p. 39) como “[...] uma investigação empírica que investiga um fenômeno contemporâneo em profundidade e em seu contexto de vida real [...]”. Além disso, como técnica de pesquisa, realizaram-se entrevistas com pessoas da comunidade, sob os critérios de: contato com a biblioteca, quando do seu funcionamento e/ou até os dias atuais; maior idade, ou seja, pessoas mais antigas com contato com biblioteca/comunidade e conhecimento da história local.

Para manter o registro e orientação quando realizada a coleta de dados, fez-se uso dos instrumentos diário de campo e protocolo, este último definido como documento não formal e norteador dos procedimentos tomados ao longo da pesquisa. A análise dos materiais coletados foi realizada sob o prisma da análise de conteúdo. Segundo Henry e Moscovici (1968, tradução nossa) a análise de conteúdo é uma técnica usada para tratar materiais narrativos, linguísticos, que podem ser coletados por meio de enquetes ou entrevistas, artigos de jornal, histórias, testemunhos, obras literárias, entre outros.

Conclui que a Biblioteca da Sociedade de Leitura, Canto e Jovialidade possui um importante papel na construção da memória e fortalecimento da identidade cultural da comunidade, pois além da interação que a mesma possibilita entre os membros da comunidade, mantém o acervo bibliográfico em alemão gótico, demonstra interesse em divulgar as raízes da sua história cultural. Assim, a biblioteca comunitária se constitui um lugar de memória.

\section{Bibliotecas comunitárias, memória e identidade cultural}

As bibliotecas comunitárias configuram-se tema pouco abordado na literatura acadêmico-científica, o que acarreta inexistência de histórico e conceitos unanimemente reconhecidos sobre as mesmas, bem como certa divergência entre os autores sobre a distinção conceitual e/ou funcional entre bibliotecas comunitárias, públicas e populares. 
As divergências conceituais e/ou funcionais entre bibliotecas comunitárias, públicas e populares englobam também o emprego do termo "biblioteca comunitária". Almeida Júnior (1997) defende que o termo biblioteca comunitária teve sua origem na proposta de integração entre biblioteca pública e biblioteca escolar, utilizado como forma de amenizar as ideias que acompanhavam a proposta de bibliotecas populares, “[...] tornando-as mais compatíveis, adequadas e assimiláveis pela classe dominante. Seu objetivo era modificar a atuação da biblioteca pública, mantendo, no entanto, suas concepções básicas." (ALMEIDA JÚNIOR, 1997, p. 93).

Machado (2008) na sua tese "Bibliotecas comunitárias como prática social no Brasil”, corrobora com Almeida Júnior (1997) quanto ao surgimento das bibliotecas comunitárias em regiões periféricas, se referindo aos novos espaços de leitura onde a população tem maior dificuldade de acesso à informação, cultura, educação de qualidade e serviços públicos em geral. Machado (2008, p. 16) complementa a questão desse novo espaço formado "[...] a partir de ações locais coletivas, baseadas em atitudes criativas e solidárias e lideradas por grupos que tomam para si o desafio de solucionar a carência da leitura e do acesso à informação, numa luta contra a crescente exclusão social." Para a autora, as bibliotecas comunitárias surgem "[...] como práticas espontâneas, idealizadas e implementadas por agentes individuais ou coletivos; cidadãos comuns, com ou sem instrução formal, com ou sem apoio institucional.” (MACHADO, 2009, p. 49).

Almeida Júnior (1997, p. 107), afirma que as bibliotecas comunitárias “[...] não representam um tipo específico de biblioteca, diferente das bibliotecas públicas, pois não possuem características específicas que as constituam em algo novo." Como possuem os mesmos objetivos e normalmente os mesmos serviços que as bibliotecas públicas, as bibliotecas comunitárias apenas representam uma proposta de atuação destas.

Apesar de considerar as bibliotecas comunitárias extensão das bibliotecas públicas, Almeida Júnior (1997), aborda o que talvez pudesse ser a principal diferença entre as duas - a participação da comunidade - no que diz respeito ao gerenciamento da biblioteca e na determinação de políticas e de objetivos que norteiam e direcionam sua atuação, salientando assim um sentido social à biblioteca. O autor conclui que: "A participação da comunidade na gestão da biblioteca: [...], é entendida de maneira a 
simplesmente buscar o conhecimento do que cada comunidade necessitaria e gostaria de obter nos espaços ocupados pelas bibliotecas." (ALMEIDA JÚNIOR, 1997, p. 106).

Em relação à participação da comunidade, Machado (2008) exemplifica o desenvolvimento da uma biblioteca pública e comunitária ${ }^{2}$, a primeira legalmente criada pelo governo municipal e que ao longo dos anos foi perdendo usuários; e a segunda por membros de uma cooperativa de catadores de lixo que teve sua continuação ampliada, dando margem à percepção do surgimento da biblioteca comunitária como um "[...] poder subversivo de um coletivo, uma forma de resistência contra-hegemônica, de quase enfrentamento social, numa nova realidade, que escapa das medidas e das categorias descritivas existentes [...]" (MACHADO, 2008, p. 51).

Machado (2008) identifica outras particularidades que distinguem bibliotecas comunitárias de públicas: são criadas efetivamente pela comunidade e não para a comunidade, provenientes de uma ação cultural; possuem perspectiva comum do grupo ao combate à exclusão informacional, pela luta pela igualdade e justiça social; localizamse em regiões periféricas; não são instituições governamentais e não possuem vinculação direta com Municípios, Estados ou Federação.

Pelo exposto, entendemos a biblioteca comunitária como:

Um projeto social que tem por objetivo, estabelecer-se como uma entidade autônoma, sem vínculo direto com instituições governamentais, articuladas com as instâncias públicas e privadas locais, lideradas por um grupo organizado de pessoas, com o objetivo comum de ampliar o acesso da comunidade à informação, à leitura e ao livro, com vistas à sua emancipação social. (MACHADO, 2009, p. 91).

Conforme Sarti, Guiraldeli e Vicentini (1984), os objetivos das bibliotecas comunitárias consistem em apresentar critérios para a planificação de espaços e serviços em bibliotecas instaladas em áreas periféricas e carentes socioeconomicamente, bibliotecas que seriam pontos de leitura. Nesse prisma, os autores apontam que os objetivos das bibliotecas comunitárias consistem em atender a uma comunidade específica, desenvolver o hábito da leitura uma vez que tais finalidades auxiliam na conscientização da população quanto à importância da participação comunitária e

\footnotetext{
${ }^{2}$ Biblioteca Pública Alceu Amoroso Lima e Biblioteca Comunitária Ler é Preciso da Coopamare, ambas localizadas no bairro de Pinheiros, na cidade de São Paulo.
} 
preservação de um bem público, bem como tornar a biblioteca integrante da comunidade.

Fortemente ligada à comunidade, Bastos (2010, p. 73) coloca que, as bibliotecas comunitárias "[...] desejam apresentarem-se como espaços que representem suas comunidades, organizados de acordo com os interesses dela." Nesse sentido, Almeida Júnior (1997) concorda com Bastos (2010), ao enfatizar aspectos voltados à necessidade de uma maior participação da comunidade nas decisões da biblioteca, de modo que os serviços e trabalhos prestados por esta sejam adequados e atendam o modo de vida da comunidade.

A comunidade, conforme Machado (2008), se estabelece como grupo formado por moradores de um mesmo local que se unem por afinidades e objetivos comuns e elegem um espaço para se encontrar, construindo histórias e criando novos caminhos.

Os espaços eleitos para construir histórias e criar novos caminhos então se configuram como território de práticas culturais identitárias, onde se concentram as energias e forças sociais da comunidade, promovendo a coesão social, o "[...] local da memória, da língua, da cultura [...]” (GOHN, 2005, p. 18). Desta forma, a biblioteca comunitária se constitui um lugar de memória.

\section{A biblioteca comunitária como lugar de memória e construtor da identidade cultural}

Percebida através da história, a biblioteca organiza-se, permitindo a reconstituição de sua presença na sociedade. Verri (1996, p. 29), relata que "[...] é do desejo de agir, registrar, lembrar e da necessidade de divulgar ou ampliar ideias e lutas que as bibliotecas se formam. E se ordenam e se articulam para acumular, produzir, reproduzir e difundir o resultado da atividade criadora do homem." A biblioteca constitui-se e serve a diferentes interesses, atravessando as classes sociais, tornando-se campo onde se acumulam tradições, inovações, afirmações, negações, contradições, oposições, configurando-se como uma instituição que, por meio dos registros, se relaciona e é impulsionada pelo desenvolvimento e movimento histórico do homem (VERRI, 1996).

Conforme Maurice Halbwachs (2006), a memória coletiva dos contextos sociais é uma construção histórica. O contexto social compreendido como o espaço-tempo em que se processam as práticas coletivas objeto da memória que, sob pena de extinção, tem na história seu recurso de retenção. Para o autor: 
A necessidade de escrever a história de um período, de uma sociedade e até mesmo de uma pessoa só desperta quando elas já estão bastante distantes no passado para que ainda se tenha por muito tempo a chance de encontrar em volta diversas testemunhas que conservam alguma lembrança. (HALBWACHS, 2006 p. 101)

Para Halbwachs, a construção da memória é uma estratégia de agentes e agências sociais para ancorar identidades, pois, conforme o autor, existe uma "[...] ligação fenomenológica muito estreita entre a memória e o sentimento de identidade." (HALBWACHS, 2006, p. 204). Nesse sentido, as práticas de leitura também podem ser analisadas como estratégias e práticas de memória.

Em outra perspectiva teórica, García-Canclini (1997) lembra da necessidade de criar mitos e monumentos de preservação do passado como marcos fundamentais de construção de identidades, inclusive os documentos escritos se enquadrariam neste processo. Segundo o autor:

[...] ter uma identidade seria, antes de mais nada, ter um país, uma cidade ou um bairro, uma entidade em que tudo o que é compartilhado pelos que habitam esse lugar se tornasse idêntico ou intercambiável. Nesses territórios a identidade é posta em cena, celebrada nas festas e dramatizada também nos rituais cotidianos. (GARCÍA-CANCLINI, 1997, p. 190)

As práticas de leitura de livros ou documentos são rituais que possibilitam a preservação do passado e as bibliotecas são os espaços onde eles são armazenados.

A biblioteca comunitária caracteriza-se como um lugar de memória. Thiesen (2009) afirma que nas últimas décadas, passou-se a denominar arquivos, bibliotecas e museus como lugares de memória, segundo teorias cunhadas por autores franceses. Thiesen (2009, p. 65) pontua que “[...] lugares de memória são portadores de identidades dos povos que eles representam, formadores e reprodutores da memória coletiva de grupos e nações."

Os lugares de memória, de acordo com Nora (1993), são lugares material, simbólico e funcional, simultaneamente e somente em graus diversos. Mesmo um lugar de aparência puramente material, como um depósito de arquivos, só é lugar de memória 
se a imaginação o investe de uma aura simbólica. Então, esses três aspectos dos lugares de memória - material, simbólico e funcional - coexistem sempre e o que os constitui é um jogo da memória e da história, uma interação dos dois fatores que leva a sua sobredeterminação recíproca.

Como afirma Nora (1993, p. 15): “O que nós chamamos de memória é, de fato, a constituição gigantesca e vertiginosa do estoque material daquilo que nos é impossível lembrar, repertório insondável daquilo que poderíamos ter necessidade de nos lembrar." Como lembra Pomian (2000, p. 507): “Toda memória é em primeiro lugar uma faculdade de conservar os vestígios do que pertence já em si a uma época passada." Os vestígios do passado podem ser transmitidos sob a forma de criações exteriores ao próprio organismo, capazes de uma existência autônoma em relação a este, como os relatos que passam de narrador em narrador, conservando alguns elementos da sua identidade e também o caso dos escritos, entre outros.

Nesta perspectiva, a memória é o que permite a um ser vivo remontar no tempo, relacionar-se, sempre se mantendo no presente, com o passado. Essa volta ao passado é sempre indireta, pois entre este e o presente, interpõem-se sinais e vestígios mediante os quais se podem compreender o passado, como as relíquias, recordações, imagens. É também imperfeita, porque o passado não pode ser simplesmente restituído na sua íntegra, além do quê, toda a reconstrução é sempre marcada pela dúvida, como as recordações pessoais, um misto de impressões vívidas e fantasia e também quando a reconstrução do passado se funda em vestígios, imagens ou relíquias, os suportes da memória coletiva. Indireta, imperfeita, incerta (POMIAN, 2000).

Os monumentos continuam a fornecer uma imagem social da eternidade e da transcendência da história. E essa função patrimonial implica uma lógica da conservação com suas formas e seus ideais. O reconhecimento de uma herança cultural e sua transmissão não se relaciona somente com preocupações políticas, ele supõe a continuidade de uma representação da história, tanto das ideias quanto dos acontecimentos. Assim, a própria ideia de patrimônio, ainda que nem sempre de modo consciente, perdura desde a Revolução Francesa como modo de reprodução das mentalidades coletivas (JEUDY, 1990, p. 5). 
Bernd (1994) coloca que nas sociedades sem escrita, os “homens-memória” eram os responsáveis pela memória da coletividade, por guardar as genealogias, códices, provérbios, feitos da aldeia, assim garantindo a coesão do grupo. Na transição da memória oral à escrita, constitui-se a história, que representou a conquista definitiva pelo homem, de seu passado coletivo.

A autora complementa esta questão ao pontuar que história e memória confundem-se e têm o papel como pivô, pois é a partir da memória coletiva que se constrói e se consolida a identidade de um grupo. A noção de pertencimento tem a ver com enraizamento, com a herança e a produção de um acervo cultural em comum. Quando as configurações sociais se alteram, parece uma nova forma de interação, sujeito/sociedade, que vai influenciar no modo do sujeito se constituir, de estruturar sua identidade, já que a identidade é tida como o processo individual construído por meio do ir e vir entre sujeito e o mundo social, mas que surge a partir do pertencimento a algum grupo (BARRETO, 2006).

Entretanto, os grupos constroem suas identidades culturais a partir de suas práticas sociais. A leitura se constitui uma dessas práticas e possui múltiplas finalidades. Conforme Morais (1995) a leitura é um meio precioso para enriquecer o vocabulário, é um meio extraordinário de transmissões de informações e conhecimentos. Além disso, possibilita acesso ao saber, ajuda a refletir e compreender a realidade do mundo que nos cerca. A leitura é uma prática associada à biblioteca.

Com a finalidade de perceber a importância da Biblioteca Comunitária da Associação de Leitura e Canto Jovialidade de Linha Andréas para a comunidade, a seguir passamos à caracterização do seu espaço, acervo e o significado do seu acervo para os membros da comunidade. Os nomes dos narradores são fictícios para resguardar a privacidades de nossos entrevistados.

\section{A biblioteca comunitária em Linha Andréas: história, espaço e memória}


Linha Andréas é uma das localidades que integra o $8^{\circ}$ Distrito do município de Venâncio Aires, denominado Vale do Sampaio, com sede em Vila Terezinha. Uma parte de Linha Andréas também pertence ao Distrito de Deodoro, bem como a identidade histórica. (RICHTER, 2007). A economia de Linha Andréas é baseada na agricultura de minifúndio de fumo, milho e culturas de subsistência, pois o aproveitamento da sua terra é reduzido pelas escarpas e arroios, possuindo assim pouca terra arável. A indústria resume-se ao artesanato local (RICHTER, 1998).

A formação da "Sociedade" de "Linha Andréas" remete-nos ao ano de 1892. De acordo com Flores (1983, p. 183), apenas 16 anos após o povoamento das Linhas Santana e Andréas, no vale do Alto do Sampaio, os imigrantes boêmios criaram, em 3 de janeiro de 1892, a Sociedade de Canto Frohsinn (Jovialidade). Frohsinn que "[...] traduz o estado de ânimo e a maneira de ser do imigrante alemão, apreciador de festas, nas quais se alegrava bebendo bier e cantando 'Lieder' no folclore de seus ancestrais, cultivando assim as tradições que lhes legaram." A par do canto, diversos moradores de Alto Sampaio sentiam falta de um aprimoramento cultural, 'para melhorar os costumes'. Desejavam fundar uma Sociedade de Leitura, como houvera na pátria de origem. Em uma reunião, alguns presentes decidiram lançar as raízes da Sociedade de Leitura, fundada no ano de 1900, Schmidt (1923) coloca: “[...] por meio da leitura buscava refrigério para a alma enquanto o corpo descansava da pesada faina na selva: ao meio dia, nas longas noites hibernais, e principalmente nos domingos e dias santificados."

A leitura colocava o imigrante em contato com os valores éticos e étnicos de seus ancestrais, e serviu para dar prosseguimento a lastro 'Deutschtum', isto é, de cultivo da cultura germânica existente nas colônias. Todavia, a leitura não proporcionava convívio social efetivo, capaz de extravasar sentimentos de sociabilidade que o colono acalentava em sua alma. (FLORES, 1983, p. 183)

Schmidt (1923) explica que surgiu então o desejo de colocar algo social na Sociedade de Leitura. Logo veio a ideia de anexarem a Sociedade de Canto, inativa há um ano por falta de dirigente. Em assembleia no dia 27 de agosto de 1904, decidiram os membros fundir as duas instituições, salvando a Sociedade de Canto e formando então a Sociedade de Canto e Leitura Frohsinn (Jovialidade). Richter (1998) coloca que, em 
virtude da crise que a Sociedade de Canto atravessava, o nome Leitura antecedeu o de canto. Denominou-se então Sociedade de Leitura e Canto Jovialidade, que a partir de 2005, passou a denominar-se Associação de Leitura e Canto Jovialidade de Linha Andréas.

Atualmente, a sede da A.L.C.J. de Linha Andréas, conserva sua fachada original, com exceção do telhado para proteção dos carros e os anexos à direita, em alvenaria, que abrigam a atual sala da Biblioteca (Figura 1):

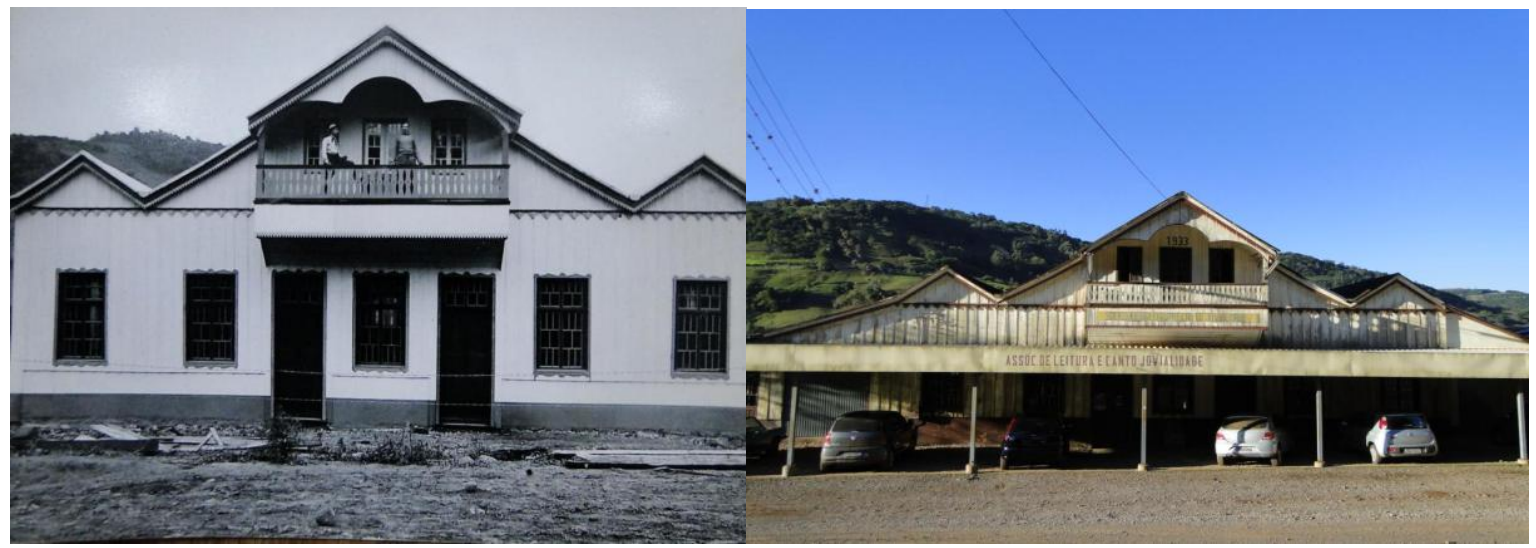

Figura 1 - Fachada original e atual da A.L.C.J. de Linha Andréas Fonte: Sehn (2013b)

A Biblioteca Comunitária localiza-se em uma sala construída à direita da entrada da sede. Os entrevistados não souberam descrever quando foi feita esta reforma, mas foi localizado no Livro-Ata de 1986 a 1992, na ata de 5 de dezembro de 1989 (ATA, 1989), que nos próximos dias ao citado da ata, seriam concluídas as obras da nova biblioteca para que pudesse ser feita a transferência dos livros para mesma, já que a antiga não oferecia as condições adequadas.

Em 2011, a sala atual novamente sofreu uma intervenção, pela Secretaria de Cultura de Venâncio Aires, que estava providenciando a revitalização do espaço da biblioteca comunitária, com nova pintura, revitalização do armário antigo e confecção de outro armário para melhor acomodar os livros. O acervo encontra-se guardado nestes armários, conforme Figura 2: 


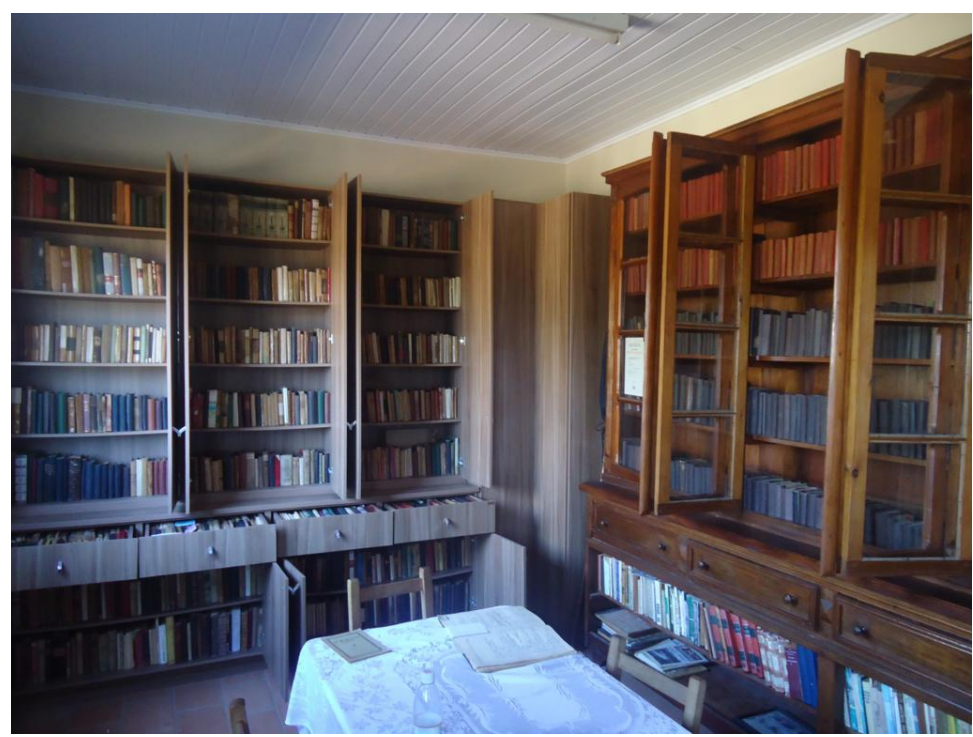

Figura 2 - Armários onde são guardados os livros. Fonte: Sehn (2013a)

Quanto ao acervo da biblioteca comunitária, alguns livros foram comprados pela Livraria do Globo, de Porto Alegre, outros doados pelos imigrantes e outros trazidos da Alemanha. Localizou-se no acervo a indicação de compra também pela livraria Hermann, da mesma cidade, conforme a etiqueta constante na segunda capa do livro Tagebucher aus Vier Weltteilen (O diário das quatro partes do mundo), publicado em 1926 (Figura 3).

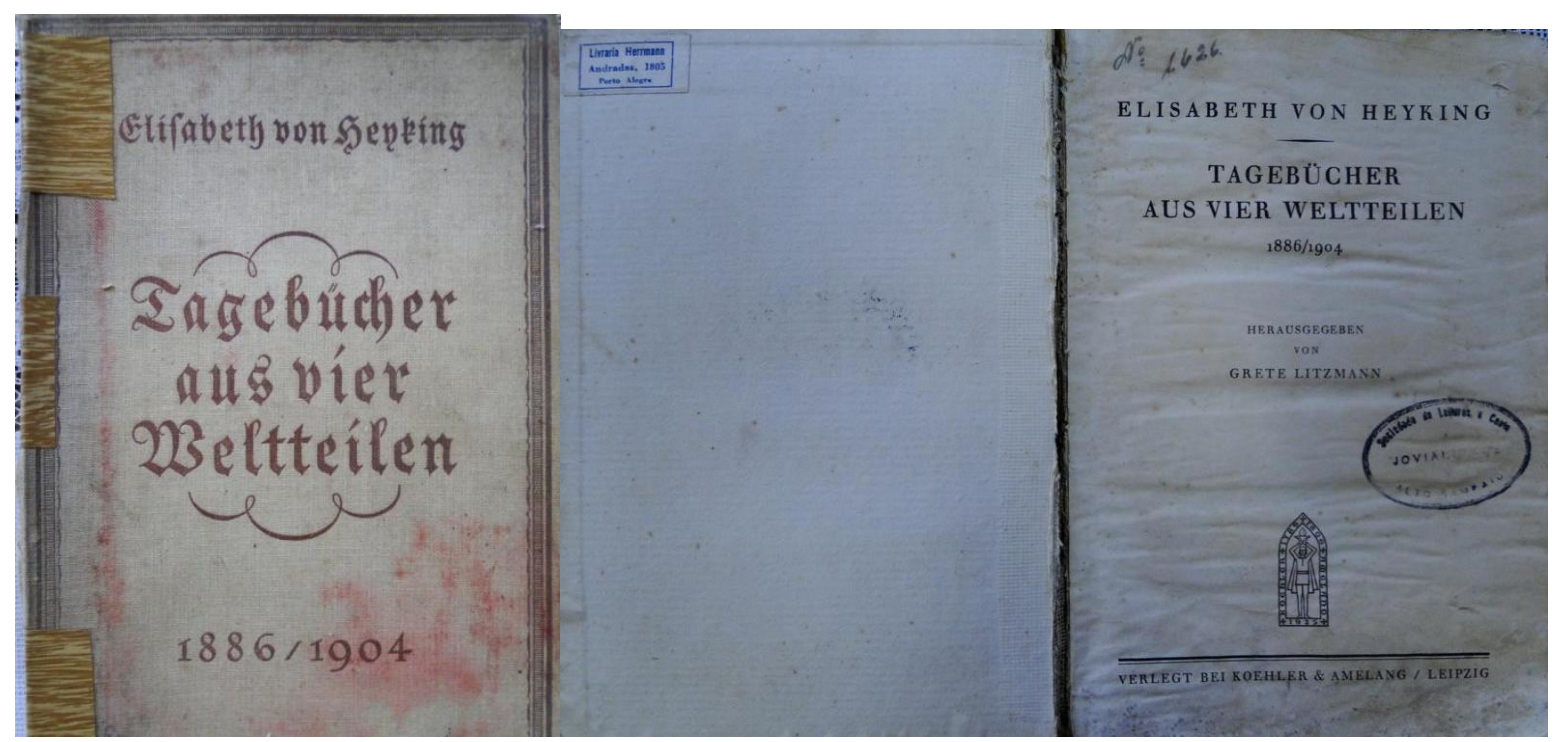

Figura 3 - Tagebucher aus Vier Weltteilen

Fonte: Sehn (2013c) 
No catálogo da biblioteca, registro de obra 1.626, consta o título do livro acima ilustrado seguido pelo valor de compra - $\operatorname{Cr} \$ 40,00$ (quarenta Cruzeiros), moeda existente no Brasil de 1942 a 1967, 1970 a 1986 e de 1990 a 1993. Os anos impressos na capa e folha de rosto - 1886 e 1904 - representam o período de que trata a temática do livro. Além dos livros, outros documentos foram encontrados na Biblioteca Comunitária da "Sociedade" como o livro de fundação da sede, atas, entre outros.

O acervo da biblioteca caracteriza-se por ser composto, quase que na sua totalidade, por livros na língua alemã, alemão gótico e, minoritariamente, livros na língua portuguesa e alguns exemplares em latim. A escrita gótica, conforme Ferreira (1986, p. 1.024), é o tipo de letra "[...] angulosa e de linhas quebradas, formada entre os séculos XII e XIII, mediante progressivo fraturamento dos traços da letra carolina." Segundo Layon (1990) em alguns países da Europa a escrita gótica sobreviveu até o século XVIII e na Alemanha, até 1945.

Constatou-se, por meio de análise temática de alguns livros e do catálogo da biblioteca, que as obras referem-se à literatura de entretenimento e história, sobressaindo o gênero literário narrativo, tratando-se de histórias, romances, romances policiais, contos, novelas, sexo, histórias infantis, expedições e histórias de outras terras e países, incluindo a Alemanha. Os livros em português, na sua maioria, também se caracterizam por literatura de entretenimento, porém existem vários exemplares sobre a história e geografia do Brasil e Rio Grande do Sul, desconsiderando livros didáticos.

O acervo conta também com dicionários, vários exemplares da revista Seleções, revistas RDA (Revista da Embaixada da República Democrática Alemã na República Federativa do Brasil), revista Skt. Paulusblatt (revista em língua alemã, fundada em 1912, editada em Nova Petrópolis-RS), livros de canções fúnebres para coral masculino - 19 Grablieder für Männerchor.

A biblioteca também se configura como depositária e guardiã dos livros e documentos administrativos da A.L.C.J, entre: livros de atas dos anos de 1892 a 1942, 1919 a 1952 (tradução do anterior), 1953 a 1974, 1975 a 1986, 1986 a 1992 e 1992 a 2005; livro de atas do Grêmio Esportivo Avante; Estatutos da Sociedade; 
Livro de Inspeção do Trabalho; Registros de Saída (compra de materiais); Controle de Recebidos; Livro Caixa; Livro de Presença dos Sócios, fotografias da fachada original da Sociedade e dos regentes do coral, entre outros, o que denota sentido de organização dos membros da Sociedade, desde a origem desta e competência na administração da mesma, além da significância na salvaguarda dos registros se em algum momento fosse necessário recorrer a estes para qualquer importância.

A maioria dos livros existentes na biblioteca comunitária da A.L.C.J, tratam de literatura de entretenimento, porém, encontrou-se o título Aus meinem Leben (Da minha vida) ${ }^{3}$, a autobiografia famosa de Augus Bebel (1840-1914), social democrata alemão e um dos fundadores do Partido Social-Democrata da Alemanha (SPD). É uma obra dividida em três volumes, que no catálogo da biblioteca encontram-se registrados, com os números de volume 237, 238 e 239, sob o número de obra 196. Está registrado também o nome do autor e editora no catálogo.

A importância do acervo em alemão, da Biblioteca Comunitária de Linha Andréas, para os habitantes da comunidade, é expressa tanto em relação aos sócios atuais da "Sociedade", como aos seus antepassados. Em relação a esses últimos segue a narrativa:

Bem aquela época olha eu vejo assim, os nossos antepassados, assim, bom isto aqui não tem mais quase pessoa de idade ali, então isso praticamente todos liam o alemão e sabiam ler né então alguns aprenderam dos pais, dos vôs e como eu aquela vez também aprendo um pouco e depois ficou fora né... eles tava interessados porque desde de infância mal sabia e depois foram aprendendo e acharam que era um livro muito bom para ler o alemão mesmo, mas o alemão mesmo, escrito em alemão né, não o latim, então eles ficaram assim! Não sei e era uma novidade para eles saber ler o alemão, né! (César, 66 anos)

A narrativa evidencia a identidade cultural étnica dos antepassados em que a língua alemã se constitui em uma de suas expressões. O aprendizado da língua transmitido através da família fortalece os vínculos afetivos e familiares e, consequentemente, reforça a identidade cultural ${ }^{4}$.

\footnotetext{
${ }^{3}$ Disponível em: <http://dietz-verlag.de/isbn/9783801202453/Aus-meiném-Leben-August- Bebel>.

${ }^{4}$ Para aprofundar essa discussão ver SEYFERTH, Giralda. Imigração e diferenciação cultural: algumas questões conceituais. In: ZANINI, Maria Catarina et al. Migrantes ao Sul do Brasil. Santa Maria: ADUFSM, 2010.
} 
Evandro, 83 anos, atribui a importância do acervo em língua alemã "[...] como uma recordação hoje em dia para a juventude, os antepassados organizaram esses biblioteca aqui e funciona ainda hoje assim, assim... pra juventude se alembrar e contar um pouquinho dos antepassados." Esta narrativa revela a importância e a necessidade de deixar um legado cultural aos jovens.

Sandro, 53 anos atribui o acervo a um “[...] patrimônio [...] é um orgulho pra nossa comunidade ter isso aqui, preservar isso aqui, mas é por isso né!” Ele salienta que não lê os livros em alemão, para ele, não têm utilidade, mas considera o acervo como patrimônio da comunidade, um orgulho, pois denota ligação com os ascendentes, com o trabalho que os mesmos tiveram ao implantar a biblioteca na comunidade e o prazer em ler os livros, na época. Isso demonstra que para as gerações mais velhas a leitura em língua alemã os aproximava da Alemanha e do "Deutschtum". No presente, o acervo possui outra significação diferente, ele é motivo de "orgulho", possui um valor que dá distinção à ascendência alemã e aos seus valores e tradições a ela associados.

Eliane, 60 anos considera o acervo uma relíquia para os leitores:

Pra eles devem ter sido uma relíquia né, pra mim não porque na época eu não sabia ler né, mas hoje eu sei ler alemão também. Claro que tem muito linguajar que a gente tem que recorrer ao dicionário, mas para eles deve ter sido uma relíquia, uma coisa assim muito fantástica, eles terem isso pra lançar mão quando eles queriam ler né!

Dionísio, 87 anos, considera o acervo um importante passatempo, frisando seu possível término devido à publicação atual de livros na língua portuguesa: “Ora isto eu acho que é mais para os velhos que existem ainda, ter um passatempo né, porque eram acostumados, gostavam de ler e por isso com o tempo, vai terminar porque depois é mais só o livro escrito em língua brasileira [...]"

Jonas, 31 anos, considera que

os livros significavam para os imigrantes um refúgio aos seus problemas, um alento à distância de sua terra:

As pessoas liam esses livros e as pessoas se entrosavam, ficavam mais alegres, buscavam forças nesses livros para superar os seus problemas porque eles tinham muitos problemas para superar toda esta vinda, imagina só! Eles vieram para cá, eles se desligaram de seus familiares lá [...] as pessoas sofriam com isso, elas tinham que buscar alguma coisa pra se distrair, para esquecer, pois além de se desligar de seus familiares, os imigrantes encontraram muitos problemas aqui... quando eles chegaram aqui, eles viram que as condições de vida não era toda aquela propaganda feita pelo governo. Então eles tinham que trabalhar muito 
pesado [...] eu penso que principalmente estes livros contribuíram para dar um novo impulso, um novo ânimo para os imigrantes, para que eles superassem toda aquela problemática de vinda e de adaptação ao lugar. Eu acho assim, que com a leitura deles, eles acabavam lendo, eles acabavam se distraindo, acabavam tendo um novo ânimo para a vida deles.

Quanto à importância da leitura, César, 66 anos coloca que: "Não tinha outros muitos divertimentos, eu sempre era uma pessoa muito curiosa, sempre gostei de novidades e que aconteceu há muitos anos atrás, como é que era tatata... [...] e hoje é difícil de falar, porque para nós manter isso ali [...]" O narrador prossegue explanando que sempre gostou de ler e atualmente gosta ainda mais, como também relaciona a importância da leitura com a atividade de "bibliotecário" quando exercida: "[...] se tivesse agora aquela vez [quando bibliotecário] uma pessoa que tivesse me ajudado, hoje talvez a gente tinha muito mais informações sobre isso né, mas com a gente não deu para continuar aquela vez então...pudesse ajudar a ler alemão seria bom."

Evandro, 83 anos retoma as lembranças aos antepassados, com relação à leitura, apesar de não ler livros em alemão: “[...] Eu não leio os livros alemão mas se alguém ler eu tô achando os antepassados, como é que foi, que sacrifício eles tinham pra construir uma sociedade."

Nas narrativas, a identidade é posta em cena, celebrada, ritualizada através das práticas de leitura de livros. Ao mesmo tempo, tais práticas são práticas de memória, pois possibilitam que as lembranças do passado sejam revividas.

Sandro, 53 anos, lembra de seu pai que, com assiduidade, conversava com um vizinho sobre os livros lidos em alemão, histórias que o mesmo gostava de escutar: “[...] naquele tempo era importante que meu pai [...] eu me interessei sempre das estórias que contavam nesses livros eu sempre fiquei bisbilhotando assim, a conversa deles [...] assim, se falavam o tempo todo, todos os domingos tomavam chimarrão [...]”.

Dionísio, 87 anos denota a prática da leitura como fonte de informação, conhecimento e entretenimento, constituindo também um meio eficaz de diálogo, de trocas sociais: 
Olha, pois é, o que que vô te dizer, é porque a TV a gente tá com nojo porque quando ligam a TV, tem só roubo, tem assalto, essas coisas... então e eu tô mais interessado em ler um livro que escreva alguma outra coisa que mais me interessa. Eu gosto de ler, se vocês me encontram, se eu não tô dormindo, não tô trabalhando eu tô lendo [...]

[...] sempre tá por dentro das coisas que acontecem né? porque se aconteceu ontem alguma coisa, hoje eu vou saber no jornal, aí eu fica sabendo de tudo né, alguém que não lê, aí eu posso contar, fazer uma conversa com ele, ó eu li na jornal e aconteceu isso e isso, vai acontecer e por isso tenho muitas coisas assim, a maioria também em alemão [...]

O mundo como um livro aberto é significado por Eliane, 60 anos:

Meu deus, o mundo é um livro aberto, é um mundo na frente, a gente viaja com o livro, eu adoro ler, [...] gosto muito de ler, eu leio muito e acho que todos deveriam ler mais porque hoje em dia a TV tira muito dos nossos jovens, por isto, muitos não leem porque é muita informação mal informada, né? e um livro... é tão gostoso ler um livro, então eu tô sempre lendo. Pena que aqui a gente não tem livros assim que a gente poderia... mas nós temos a nossa Biblioteca pública em Venâncio [...]

Em um sentido similar, Jonas, 31 anos, percebe que a leitura:

[...] é importante pra tudo, sem ler [...] a leitura leva a gente pra outros lugares o mundo imaginário da gente fica mais maior, mais amplo, o vocabulário da gente aumenta, a gente adquire muitos conhecimentos. A leitura é muito importante para qualquer pessoa, para assim... para aumenta o eu de cada pessoa.

Já Sandro, 53 anos, considera que a comunidade deve manter o acervo, pois “[...] é uma coisa que os antecedentes trouxeram, enquanto nós puder preservar, eu acho que é importante nós preservar, acho que tem que ser assim."

Evandro, 83 anos, considera importante manter o acervo na língua alemã, em comparação às coisas antigas que devem ser guardadas devido ao seu legado histórico, familiar, social que eles remetem:

Óia, eu acho sim, eu lá em casa também sô assim os antepassados e as coisas velhas que meu pai tem, tinha, tão guardados ainda, não deixo tirar; entreguei para meu filho agora e ele tá guardando pra mim... até trouxeram um retrato grande de meu avô que os outros não queria e tá pendurado lá na parede da onde que nóis pertence nem conhecia, ele não chegou a ter netos, faleceu cedo mas tinha família e as coisas q meu pai tinha naquele tempo seja uma coisinha pequena ou uma outra 
coisinha como um pequeno material tá lá guardado, eu não deixo tirar [...] para ter... pensar um pouco a juventude o que os velhos, como eles trabalhavam [...]

Dionísio, 87 anos, atribui a importância em manter o acervo à existência da língua alemã no Brasil, ressaltando a importância da biblioteca:

Eu acho importante enquanto que ainda existe a língua alemã aqui no Brasil e eu acho que talvez vai melhorar de novo porque muitos jovens estão estudando [...] tem aulas alemão né, para não desaparecer a língua, então eu acho interessante a biblioteca.

Eliane, 60 anos, considera a peculiaridade do acervo como fator importante para sua manutenção.

Eu acho [...] que foi tantos anos... cento e poucos anos que tá aqui né, eu acho que nós, nossos que vem depois de nós que tem que manter esta cultura, que tem que manter isto, porque é uma coisa que poucas localidades, acho que raríssimas do nosso estado tem né, então eu acho que tem que preservar sim e tem que ter esse cuidado porque é uma coisa bem histórica e cultural, né?

Jonas, 31 anos, pontua...

[...] de certa forma sim e também acho assim se é para ficar só aqui estocado como patrimônio é complicado né, havia até uma época que o museu de Venâncio, eles estavam interessados em levar este acervo para lá, isso já faz alguns anos [...] lá os livros seriam bem cuidados, armazenados e tudo. Se fosse perguntar para mim hoje, eu de certa forma seria favorável, mas ainda tem pessoas idosas, principalmente pessoas mais idosas, que são contrários a isso né, porque mexe com as raízes deles e as pessoas mais idosas ainda têm as raízes mais próximas aos seus antecessores, do que as gerações mais novas, né, então é sinal meio contraditório. O que vou dizer? Eis a questão, né? Por que da forma como eles estão aqui [livros], eles estão aqui como um patrimônio morto, é um patrimônio histórico, importante sim, mas é um patrimônio [...] estocado. Então por esta questão eu fico pensando, até que ponto será que isto é importante sabe, porque tem pessoas que não dão valor, para eles, tem muitos jovens, que nem sabem muito da existência desta biblioteca aqui, não dão valor, não querem saber, tem outros interesses sabe, então fica assim esta questão. 
Evandro, 83 anos, atribui o significado da leitura do acervo em alemão para os habitantes de Andréas, como fonte de informação sobre a vida na terra pátria, assim como no Brasil: “Óia tinha muitos alemão que veio da Alemanha isso aquilo, que eles tinham recordação da Alemanha e se alembrava [...] e tinha recordação pra eles como era lá e aqui."

Sandro, 53 anos considera a leitura do acervo como “[...] o divertimento deles [...] um divertimento que eles tinham, que nem hoje tão jogando carta, bocha e coisa, eles davam mais valor para os livros eles gostavam mais disso, aí eles liam, foi ali mais o divertimento deles [os livros era o divertimento]."

Já Jonas, 31 anos, acredita que a leitura dos livros em alemão para os habitantes de Linha Andréas: "Foi um antidepressivo... para os imigrantes, o que é hoje uma antidepressivo né, deve ter sido naquela época."

Quanto aos atuais sócios da A.L.C.J., identificou-se nas narrativas expostas, que os entrevistados demonstram e mantêm apreço sentimental ao acervo e à biblioteca. Apesar de não mais lerem a língua alemã contida nos livros, acham que a leitura ainda é uma prática importante para as pessoas, como no passado foi para seus ascendentes, como refúgio para as dificuldades e lembrança da pátria. Os atuais sócios dividem-se em dois grupos: os que querem manter o espaço e acervo da Biblioteca dentro da sede e os que preferem que o acervo seja transferido para outro local. Há ainda, os que desejariam ler os livros, se soubessem a língua e os que não veem utilidade dos livros para a leitura, seja por desinteresse, desconhecimento da língua ou precário estado físico dos livros. Mesmo não havendo consenso quanto à manutenção dos livros na sede, convergem em um ponto comum: a necessidade de preservação do acervo.

Os livros escritos em alemão são símbolos da preservação dos traços da cultura alemã que ainda sobrevive. Eles são responsáveis pelo fortalecimento do sentimento de pertença do grupo, pois possibilita que as pessoas criem os laços de identificação com sua origem, com sua história, com a identidade cultural, com a memória social. Os livros não mais lidos e com o apreço que a comunidade os confere, passam a serem objetos 
significativos. Para a comunidade, esses objetos, se constituem lugares de memória (NORA, 1993).

Além disso, como lembra Bourdieu (2007), os objetos podem conferir distinção social. Conforme o autor, os sujeitos apreendem o mundo a partir dos esquemas de percepção e de apreciação de seus habitus. Nesse processo, os objetos ofertados simbolicamente pelos grupos possuem uma grande importância, pois conferem sentidos e significados distintos a suas práticas.

Portanto, os conteúdos das narrativas dos sócios da comunidade apontam, que tanto a sede da sociedade, a biblioteca e o seu acervo, se constituem importantes elementos para a conformação identitária da comunidade. As práticas sociais do grupo: a leitura que era praticada pelos habitantes da comunidade, a cantoria do coral, o jogo de cartas e de bocha, entre outras, estão impregnadas de memórias e histórias, como revelam os narradores. Em seu conjunto, elas são responsáveis pela manutenção da memória viva, pois simbolizam o forte enraizamento da colonização alemã na região e os vínculos identitários com os valores da cultura germânica ${ }^{5}$.

\section{Considerações finais}

A Biblioteca Comunitária da Associação de Leitura e Canto Jovialidade, de Linha Andréas, se constitui um tipo singular de biblioteca. Atualmente, ela configura-se como um lugar de memória, pois reforça os vínculos comunitários entre os membros do grupo e também um espaço que celebra a origem de um passado comum, fortalecendo os laços identitários da comunidade.

A importância da comunidade e a sua preocupação em manter a biblioteca comunitária, que além de funcionar como um espaço de entretenimento pelas memórias das práticas da leitura possui um valor simbólico, pois o seu acervo de livros, em língua alemã, denota zelo pelo patrimônio material e imaterial. Ela se constitui em uma das

\footnotetext{
${ }^{5}$ Para aprofundar a discussão sobre memória e identidade étnica ver CARDOSO, Oliveira Roberto de. Identidade, etnia e estrutura social. São Paulo: Pioneira, 1976.
} 
marcas da tradição cultural germânica, pois presentifica e reatualiza as memórias dos antepassados, através das práticas de leitura ora realizadas, fortalecendo a memória cultural e o sentimento de pertença dos membros do grupo.

Hoje, a "Sociedade", como é denominada pelos moradores do local, permanece viva. Ela é frequentada quase diariamente por seus sócios, que fazem da sede um espaço de sociabilidade onde se realizam os encontros, as confraternizações, as trocas de ideias e os compartilhamentos de valores entre os membros da comunidade. Este espaço de convívio e entretenimento reúne os membros para cantar mensalmente nos ensaios do coral, para jogar cartas, bolão, tomar cerveja e chimarrão. Tornou-se um espaço cultural híbrido onde convivem pessoas descendentes com traços e costumes da cultura alemã, mas que também adotaram costumes da cultura gaúcha.

A biblioteca comunitária, através do seu acervo em língua alemã e alemão gótico, guarda inúmeros segredos que estão entranhados nas memórias dos seus moradores, pois remontam um passado comum vindo de outras terras. Os livros escritos em língua alemã, hoje não mais lidos, mas tidos como relíquias da comunidade e os costumes da tradição germânica auxiliam, reforçam, mantendo viva a identidade cultural.

As instituições são lugares de memória, pois através da guarda, conservação, ordenamento, disponibilização dos registros ajudam a manter a memória viva. Assim, a Associação de Leitura e Canto Jovialidade, através da sua sede e do acervo contido na sua biblioteca comunitária se constitui um monumento e um documento que auxilia na manutenção e no fortalecimento da identidade cultural alemã da comunidade.

Além disso, é preciso considerar que a preservação do acervo e as práticas de leituras assumem significações diversas, dependendo do contexto social, das gerações envolvidas no processo histórico e sociocultural. 


\section{Referências}

BORGES, Jorge Luis. Nova refutação do tempo. In: . Outras inquisições: obras Completas, volume II. São Paulo: Globo, 1999.

COSTA, Silvano João da. Bergson-Deleuze nos conceitos de cinema. In: MOSTAFA, S. P.; NOVA CRUZ, D. V. da Deleuze vai ao cinema. Campinas: Alínea, 2011.

DELEUZE, Gilles. Cinema 2 : a imagem-tempo. São Paulo: Editora Brasiliense, 2007.

DELEUZE, Gilles. Cursos sobre Espinoza: Vincennes, 1978-1981. Fortaleza: EDUECE, 2009.

DELEUZE, Gilles. Diferença e repetição. Rio de Janeiro: Graal, 1998.

DELEUZE, Gilles. Ilha deserta e outros textos. São Paulo: Iluminuras, 2004.

DELEUZE, Gilles. ¿Que es un dispositivo? In: . Michel Foucault, filósofo. Barcelona: Gedisa, 1990, p. 155-161.

DELEUZE, Gilles; GUATTARI, F. O que é a filosofia? São Paulo: Editora 34, 2007.

ESPINOSA, Baruch de. Ética. Tradução de Tomaz Tadeu. Belo Horizonte: Autêntica, 2009.

HUR, Domenico Uhng. Memória e tempo em Deleuze: multiplicidade e produção. Athena Digital , v.13, n., jul. p.179-190, 2013.

MOSTAFA, Solange Puntel; SILVA, Márcia Regina da; SANTARÉM SEGUNDO, José Eduardo. História cultural e ciência da informação. In: SANTARÉM SEGUNDO, José Eduardo; SILVA, Márcia Regina; MOSTAFA, Solange Puntel. Os pensadores e a ciência da informação. Rio de Janeiro: E-paper, 2012.

NORA, Pierre. Entre memória e história: a problemática dos lugares. São Paulo: PUC-SP, 1993. (Projeto História, n. 10.)

OLIVEIRA, Eliane Braga de; RODRIGUES, Georgete Medleg. O conceito de memória na Ciência da Informação: análise das teses e dissertações dos programas de pós-graduação no Brasil. Rio de Janeiro, Liinc em Revista, v. 7, n. 1, mar. p.311-328, 2011.

ROTHBERG, Michael. Introduction: between memory and memory: from lieux de mémoire to noeuds de mémoire. JSTOR (Journal Storage) n. 118/119, p.3-12, 2010.

SHAVIRO, Steven. Deleuze's Encounter With Whitehead. [200-]. Disponível em: <http://ftp.shaviro.com/Othertexts/DeleuzeWhitehead.pdf>. Acesso em: 16 jun. 2014. 
Memória, identidade cultural e biblioteca comunitária: um estudo de caso em Linha Andréas, em Venâncio Aires - RS

Valdir Jose Morigi - Ana Paula Sehn

Recebido em: 04/08/2014 Aprovado em: 01/10/2014 revistapercursos@gmail.com 